\title{
Prostate-specific antigen bounce following stereotactic body radiation therapy for prostate cancer
}

\section{Charles C. Vu ${ }^{1,2}$, Jonathan A. Haas ${ }^{1}{ }^{*}$, Aaron E. Katz ${ }^{3}$ and Matthew R. Witten ${ }^{1}$}

1 Division of Radiation Oncology, Winthrop-University Hospital, New York, NY, USA

2 Stony Brook School of Medicine, New York, NY, USA

${ }^{3}$ Department of Urology, Winthrop-University Hospital, New York, NY, USA

\section{Edited by:}

Brian Timothy Collins, Georgetown

University Hospital, USA

\section{Reviewed by:}

Sean Collins, Georgetown University

Hospital, USA

Anatoly Dritschilo, Georgetown

University School of Medicine, USA

*Correspondence:

Jonathan A. Haas, Division of

Radiation Oncology,

Winthrop-University Hospital, 264 Old

Country Road, Mineola, New York, NY

11501, USA

e-mail: jhaas@winthrop.org
Introduction: Prostate-specific antigen (PSA) bounce after brachytherapy has been welldocumented. This phenomenon has also been identified in patients undergoing stereotactic body radiation therapy (SBRT). While the parameters that predict PSA bounce have been extensively studied in prostate brachytherapy patients, this study is the first to analyze the clinical and pathologic predictors of PSA bounce in prostate SBRT patients.

Materials and Methods: Our institution has maintained a prospective database of patients undergoing SBRT for prostate cancer since 2006. Our study population includes patients between May 2006 and November 2011 who have at least 18 months of follow-up. All patients were treated using the CyberKnife treatment system. The prescription dose was 35-36.25 Gy in five fractions.

Results: One hundred twenty patients were included in our study. Median PSA follow-up was 24 months (range 18-78 months). Thirty-four (28\%) patients had a PSA bounce. The median time to PSA bounce was 9 months, and the median bounce size was $0.50 \mathrm{ng} / \mathrm{mL}$. On univariate analysis, only younger age $(p=0.011)$ was shown to be associated with an increased incidence of PSA bounce. Other patient factors, including race, prostate size, prior treatment by hormones, and family history of prostate cancer, did not predict PSA bounces. None of the tumor characteristics studied, including Gleason score, pre-treatment PSA, T-stage, or risk classification by NCCN guidelines, were associated with increased incidence of PSA bounces. Younger age was the only statistically significant predictor of PSA bounce on multivariate analysis $(\mathrm{OR}=0.937, p=0.009)$.

Conclusion: PSA bounce, which has been reported after prostate brachytherapy, is also seen in a significant percentage of patients after CyberKnife SBRT. Close observation rather than biopsy can be considered for these patients. Younger age was the only factor that predicted PSA bounce.

Keywords: PSA, SBRT, SAbR, prostate cancer, CyberKnife

\section{INTRODUCTION}

Prostate cancer remains the most commonly diagnosed noncutaneous cancer in men (1). Stereotactic body radiation therapy (SBRT) is an emerging modality in the treatment of lowand intermediate-risk prostate cancer, with several series showing excellent local control and toxicity (2-5).

Prostate-specific antigen (PSA) bounce after brachytherapy has been well-documented (6-9). The etiology of this phenomenon is unclear; proposed explanations include laboratory error (10), a delayed radiation effect (8), and prostatitis secondary to needle insertion (11). PSA bounce has also been identified in three-dimensional conformal radiation therapy (3D-CRT) (12) and intensity-modulated radiation therapy (IMRT) (13). There have been a limited number of studies reporting the incidence of PSA bounce after SBRT, which has varied from 17 to $31 \%$ in the literature $(2-5,14)$. While the clinical, pathologic, and dosimetric parameters that predict PSA bounce have been extensively studied in patients undergoing permanent seed prostate brachytherapy, to our knowledge no study has performed a similar analysis in patients undergoing SBRT. This study reports our institution's incidence of PSA bounce in prostate SBRT, as well as performs an analysis of clinical and pathologic predictors of PSA bounce in this patient population.

\section{MATERIALS AND METHODS PATIENT POPULATION}

Our institution has maintained a prospective database of patients undergoing SBRT for prostate cancer since 2006. This study was approved by our hospital's institutional review board. One hundred twenty patients with organ-confined prostate cancer treated between May 2006 and November 2011 with follow-up of at least 18 months were included. No patients were treated with hormones during or following treatment, but patients with prior treatment with hormones were included. 


\section{TREATMENT TECHNIQUE}

All patients were treated using the CyberKnife treatment system. The CyberKnife system consists of a 6-MV linear accelerator mounted on a robotic arm. There are two orthogonal kilovoltage $\mathrm{X}$-ray imagers that provide real time image guidance and automatic correction for movement of the prostate throughout the treatment. Approximately 2 weeks before treatment planning, four fiducial seeds were placed transperineally in each patient to allow for motion tracking during treatment. The four implanted seeds were positioned with two at the prostate apex and two at the base. After allowing approximately 1 week for possible seed migration, treatment planning was performed prior to the treatment day using a CT scan (1.5-mm cuts) fused to an MRI. All pre-treatment imaging was performed with the patient in the same position used for treatment delivery. For low-risk patients, the prostate alone was the gross target volume (GTV). For intermediate- to high-risk patients, the proximal half of the seminal vesicles was added to the GTV if the Gleason Score $>6$ and the PSA $>10 \mathrm{ng} / \mathrm{mL}$. Following delineation of the GTV, a margin was added to create the planning target volume (PTV). For low- and intermediate-risk patients, the margin was $5 \mathrm{~mm}$ throughout except posteriorly by the rectum where a 3-mm margin was used. For high-risk patients, an 8-mm margin was added on the involved side. Target tracking and patient positioning were accomplished by registering the location of the fiducial markers in the real time images to their planning CT location. The robotic delivery system automatically adjusts the linear accelerator position to correct for both rotational and translational movement of the patient and prostate during treatment. The total clinical accuracy for treatment is less than $1 \mathrm{~mm}$. Treatments were delivered on five consecutive days. Patients had a bowel preparation prior to treatment, including Dulcolax (Boehringer, Germany) and a fleet enema on the morning of each treatment. Additionally, patients received $1500 \mathrm{mg}$ of amifostine (MedImmune, LLC, Gaithersburg, MD, USA) mixed in saline as a rectal suppository at least 15-20 min prior to each treatment as a radioprotectant. The prescription dose was $35-36.25$ Gy in five fractions.

\section{FOLLOW-UP}

Routine PSA follow-up was performed at 3-month intervals for the first 2 years, 4-month intervals for the following year, and 6month intervals thereafter. PSA bounce was defined as a rise of $0.2 \mathrm{ng} / \mathrm{mL}$ above a patient's PSA nadir, followed by a decline in PSA to below that nadir (6). Time to PSA bounce was calculated from the first PSA measurement that was $\geq 0.2 \mathrm{ng} / \mathrm{mL}$ above the patient's nadir (8). PSA bounce size was defined from the PSA nadir to the subsequent PSA peak before falling below the prior nadir.

\section{STATISTICAL ANALYSIS}

Univariate analysis was performed using Pearson chi-squared tests for categorical variables and Mann-Whitney $U$ tests for categorical variables. Multivariate analysis was performed using logistic regression. All statistical analysis was done in SPSS 21 (IBM, Armonk, NY, USA).

\section{RESULTS}

One hundred twenty patients were included in our study. Demographic, tumor, and treatment characteristics are summarized in
Table 1 | Patient and tumor characteristics

\begin{tabular}{ll}
\hline Age & $68.1(47-88)$ \\
Prostate size & $69.9(24-201)$ \\
Pre-Tx PSA & $5.5(1-34)$ \\
NCCN RISK & \\
Low & $69(58 \%)$ \\
Intermediate & $38(32 \%)$ \\
High & $13(11 \%)$ \\
GLEASON SCORE & \\
$\leq 6$ & $73(61 \%)$ \\
7 & $35(29 \%)$ \\
8 & $10(8 \%)$ \\
9 & $1(1 \%)$ \\
Unknown & $1(1 \%)$ \\
DOSE & \\
19.5 & $2(2 \%)$ \\
21 & $4(3 \%)$ \\
35 & $63(53 \%)$ \\
36.25 & $51(43 \%)$ \\
T-STAGE & \\
T1 & $102(85 \%)$ \\
T2 & $17(14 \%)$ \\
Recurrence & $1(1 \%)$ \\
RACE & \\
White & $88(73 \%)$ \\
Black & $14(12 \%)$ \\
Spanish & $7(6 \%)$ \\
FAMILY HISTORY OF PROSTATE CANCER & $11(9 \%)$ \\
Yes & \\
No & $27(23 \%)$ \\
PRIOR HORMONES & $93(78 \%)$ \\
No & $11(9 \%)$ \\
\hline & $109(91 \%)$ \\
\hline
\end{tabular}

NCCN, National Comprehensive Cancer Network; TX, treatment; PSA, prostatespecific antigen.

Table 1. The average age was 68.1 years (range $47-88$ years). Using NCCN guidelines, 69 (58\%) patients were low-risk, 38 patients were intermediate-risk (32\%), and 13 patients were high-risk. Seventy-three $(61 \%)$ patients were Gleason score 6 or less, 35 (29\%) patients were Gleason score 7, and 11 patients were Gleason score 8 or higher. Median prostate size was $69.9 \mathrm{~g}$ (range 24-201 g).

Median PSA follow-up was 24 months (range 18-78 months). Thirty-four $(28 \%)$ patients had a PSA bounce. The median time to PSA bounce was 9 months, and the median bounce size was $0.50 \mathrm{ng} / \mathrm{mL}$. Table 2 summarizes the univariate analysis of patient and tumor characteristics on the incidence of PSA bounces. Only younger age $(p=0.011)$ was shown to be associated with an increased incidence of PSA bounce. Other patient factors, including race, prostate size, prior treatment by hormones, and family history of prostate cancer, did not predict PSA bounces. None of the tumor characteristics studied, including Gleason score, pretreatment PSA, T-stage, or risk classification by NCCN guidelines, were associated with increased incidence of PSA bounces. On 
multivariate analysis, younger age was the only statistically significant predictor of PSA bounce (OR $=0.937,95 \%$ confidence interval $=0.892-0.984, p=0.009)$.

\section{DISCUSSION}

The reported rate of PSA bounce after SBRT has varied from 17 to $31 \%$ in the literature $(2-5,14)$. Table 3 summarizes the results of these studies. Our hospital's experience is in-line with other institutions' reported frequencies of PSA bounces. With institutions reporting PSA bounces in 3D-CRT (12) and IMRT (13), the PSA bounce phenomenon is seen in external beam radiation therapy (EBRT) as well as in brachytherapy.

Varying definitions of PSA bounce have been used in the literature. Some have used an absolute increase (e.g., $0.4 \mathrm{ng} / \mathrm{mL}$ ) from the previous PSA (9), while others have used a relative increase (e.g., 15\%) from the most recent PSA (15). The rate of reported PSA bounce will increase as lower thresholds of PSA bounce are

Table 2 | Univariate analysis of PSA bounces.

\begin{tabular}{lc}
\hline Variable & $P$-value \\
\hline PATIENT & \\
Age & 0.011 \\
Race & 1.00 \\
Family history & 0.75 \\
Prior hormones & 0.94 \\
Prostate size & 0.46 \\
TUMOR & \\
T-stage & 0.62 \\
Gleason score & 0.19 \\
Pre-Tx PSA & 0.77 \\
NCCN risk & 0.45 \\
\hline
\end{tabular}

PSA, prostate-specific antigen; Tx, treatment; NCCN, National Comprehensive Cancer Network used. For example, Stock et al. (9) reported a PSA bounce rate of $31 \%$ if a $0.1 \mathrm{ng} / \mathrm{mL}$ threshold was used, while the PSA bounce rate in the same population would be $17 \%$ if a $0.4 \mathrm{ng} / \mathrm{mL}$ threshold was used.

To our knowledge, this is the first study of the clinical factors that predict PSA bounce in prostate cancer patients undergoing SBRT. In a recently published multi-institutional phase I feasibility study of 45 patients, McBride et al. found that prostate SBRT patients with PSA bounces were younger than those who did not have a PSA bounce (5). However, their study only analyzed the effect of age and not the effects of other clinical and pathologic parameters.

The predictors of PSA bounce in patients undergoing permanent seed brachytherapy has been extensively discussed and was reviewed by Caloglu and Ciezki (7). While a multitude of different clinical, pathologic, and dosimetric parameters have been identified as predictors of PSA bounce, the authors found that only younger age has consistently been associated with PSA bounce. Our study suggests that this association can be extended to prostate cancer patients undergoing SBRT.

Sheinbein and colleagues performed an analysis of clinical, pathologic, and dosimetric parameters associated with PSA bounce in 102 patients undergoing IMRT for localized prostate cancer (13). They reported a PSA bounce rate of $32.4 \%$. Only age $\leq 70$ was associated with PSA bounces; all other parameters studied were not found to be correlated with PSA bounces.

The reasons why younger patients more frequently experience PSA bounces are unknown. One common etiology suggested is that younger men have increased androgen levels $(9,16)$. Another frequently cited explanation is the increased sexual activity in younger men $(16,17)$. Recent sexual activity could possibly lead to spurious PSA elevations, and Das et al. reported that a common cause of PSA bounces is recent ejaculation (15). However, Crook et al. found that pre-treatment potency was a univariate predictor of PSA bounce, but this association was lost on multivariate analysis (18).

Table 3 | Review of previous prostate SBRT studies.

\begin{tabular}{|c|c|c|c|c|c|}
\hline Study & $\begin{array}{l}\text { Number of } \\
\text { patients }\end{array}$ & PSA bounce definition & $\begin{array}{l}\text { PSA bounce } \\
\text { frequency }(\%)\end{array}$ & $\begin{array}{l}\text { Median bounce } \\
\text { size }(\mathrm{ng} / \mathrm{mL})\end{array}$ & $\begin{array}{l}\text { Median time to PSA } \\
\text { bounce (months) }\end{array}$ \\
\hline King et al. (4) & 41 & $\begin{array}{l}\text { Increase of } \geq 0.2 \mathrm{ng} / \mathrm{mL} \text { followed by decline } \\
\text { to or below previous nadir }\end{array}$ & 29 & 0.39 & 18 \\
\hline Lee et al. (14) & 29 & $\begin{array}{l}\text { Increase of } \geq 0.2 \mathrm{ng} / \mathrm{mL} \text { followed by decline } \\
\text { to or below previous nadir }\end{array}$ & 28 & 0.69 & 9 \\
\hline Chen et al. (2) & 100 & $\begin{array}{l}\text { Increase of } \geq 0.2 \mathrm{ng} / \mathrm{mL} \text { followed by decline } \\
\text { to or below previous nadir }\end{array}$ & 31 & 0.5 & 15 \\
\hline Katz et al. (3) & 304 & Increase of $>0.2 \mathrm{ng} / \mathrm{mL}$ from nadir & 17 & 0.55 & 30 \\
\hline
\end{tabular}

SBRT, stereotactic body radiation therapy; PSA, prostate-specific antigen. 
Limitations of this study include its retrospective design, small sample size, and relatively short follow-up period. It is possible that some factors did not achieve statistical significance because the study was underpowered and not enough patients were studied. Larger studies with longer follow-up are needed to determine if any other factors can predict PSA bounce in prostate SBRT patients.

\section{CONCLUSION}

We report the incidence of PSA bounce in our series of prostate SBRT patients to be $28 \%$, in-line with other institutions' experiences. As observed in studies that used brachytherapy or other types of EBRT, we identified age as the only clinical factor that predicts PSA bounce.

\section{REFERENCES}

1. Siegel R, Naishadham D, Jemal A. Cancer statistics, 2013. CA Cancer J Clin (2013) 63(1):11-30. doi: $10.3322 /$ caac. 21166

2. Chen LN, Suy S, Uhm S, Oermann EK, Ju AW, Chen V, et al. Stereotactic body radiation therapy (SBRT) for clinically localized prostate cancer: the Georgetown University experience. Radiat Oncol (2013) 8:58. doi:10.1186/1748717X-8-58

3. Katz AJ, Santoro M, Diblasio F, Ashley R. Stereotactic body radiotherapy for localized prostate cancer: disease control and quality of life at 6 years. Radiat Oncol (2013) 8(1):118. doi:10.1186/1748-717X-8-118

4. King CR, Brooks JD, Gill H, Pawlicki T, Cotrutz C, Presti JC Jr. Stereotactic body radiotherapy for localized prostate cancer: interim results of a prospective phase II clinical trial. Int J Radiat Oncol Biol Phys (2009) 73(4):1043-8. doi:10.1016/j.ijrobp.2008.05.059

5. McBride SM, Wong DS, Dombrowski JJ, Harkins B, Tapella P, Hanscom HN, et al. Hypofractionated stereotactic body radiotherapy in low-risk prostate adenocarcinoma: preliminary results of a multi-institutional phase 1 feasibility trial. Cancer (2012) 118(15):3681-90. doi:10.1002/cncr.26699

6. Ciezki JP, Reddy CA, Garcia J, Angermeier K, Ulchaker J, Mahadevan A, et al. PSA kinetics after prostate brachytherapy: PSA bounce phenomenon and its implications for PSA doubling time. Int J Radiat Oncol Biol Phys (2006) 64(2):512-7. doi:10.1016/j.ijrobp.2005.07.960

7. Caloglu M, Ciezki J. Prostate-specific antigen bounce after prostate brachytherapy: review of a confusing phenomenon. Urology (2009) 74(6):1183-90. doi:10.1016/j.urology.2009.01.043

8. Mitchell DM, Swindell R, Elliott T, Wylie JP, Taylor CM, Logue JP. Analysis of prostate-specific antigen bounce after I(125) permanent seed implant for localised prostate cancer. Radiother Oncol (2008) 88(1):102-7. doi:10.1016/j. radonc.2008.04.004

9. Stock RG, Stone NN, Cesaretti JA. Prostate-specific antigen bounce after prostate seed implantation for localized prostate cancer: descriptions and implications. Int J Radiat Oncol Biol Phys (2003) 56(2):448-53. doi:10.1016/S0360-3016(02) 04470-X
10. Critz FA, Williams WH, Benton JB, Levinson AK, Holladay CT, Holladay DA. Prostate specific antigen bounce after radioactive seed implantation followed by external beam radiation for prostate cancer. J Urol (2000) 163(4):1085-9. doi:10.1016/S0022-5347(05)67698-7

11. Makarewicz R, Roszkowski K, Lebioda A, Reszke J, Ziotkowska E. PSA bounces after brachytherapy HDR and external beam radiation therapy for prostate cancer. Rep Pract Oncol Radiother (2006) 11(5):217-22. doi:10.1016/S15071367(06)71066-5

12. Hanlon AL, Pinover WH, Horwitz EM, Hanks GE. Patterns and fate of PSA bouncing following 3D-CRT. Int J Radiat Oncol Biol Phys (2001) 50(4):845-9. doi:10.1016/S0360-3016(01)01557-7

13. Sheinbein C, Teh BS, Mai WY, Grant W, Paulino A, Butler EB. Prostate-specific antigen bounce after intensity-modulated radiotherapy for prostate cancer. Urology (2010) 76(3):728-33. doi:10.1016/j.urology.2009.04.074

14. Lee YH, Son SH, Yoon SC, Yu M, Choi BO, Kim YS, et al. Stereotactic body radiotherapy for prostate cancer: a preliminary report. Asia Pac J Clin Oncol (2012). doi:10.1111/j.1743-7563.2012.01589.x

15. Das P, Chen MH, Valentine K, Lopes L, Cormack RA, Renshaw AA, et al. Using the magnitude of PSA bounce after MRI-guided prostate brachytherapy to distinguish recurrence, benign precipitating factors, and idiopathic bounce. Int J Radiat Oncol Biol Phys (2002) 54(3):698-702. doi:10.1016/S0360-3016(02) 03036-5

16. Patel C, Elshaikh MA, Angermeier K, Ulchaker J, Klein EA, Chehade N, et al. PSA bounce predicts early success in patients with permanent iodine- 125 prostate implant. Urology (2004) 63(1):110-3. doi:10.1016/j.urology.2003.08.025

17. Critz FA, Williams WH, Levinson AK, Benton JB, Schnell FJ, Holladay CT, et al. Prostate specific antigen bounce after simultaneous irradiation for prostate cancer: the relationship to patient age. J Urol (2003) 170(5):1864-7. doi:10.1097/ 01.ju.0000091644.41330.2a

18. Crook J, Gillan C, Yeung I, Austen L, McLean M, Lockwood G. PSA kinetics and PSA bounce following permanent seed prostate brachytherapy. Int J Radiat Oncol Biol Phys (2007) 69(2):426-33. doi:10.1016/j.ijrobp.2007.03.031

Conflict of Interest Statement: Dr. Jonathan A. Haas has received speaker's honoraria from Accuray Inc., Sunnyvale, CA, USA. The other co-authors declare that the research was conducted in the absence of any commercial or financial relationships that could be construed as a potential conflict of interest.

Received: 09 November 2013; accepted: 14 January 2014; published online: 28 January 2014.

Citation: Vu CC, Haas JA, Katz AE and Witten MR (2014) Prostate-specific antigen bounce following stereotactic body radiation therapy for prostate cancer. Front. Oncol. 4:8. doi: $10.3389 /$ fonc.2014.00008

This article was submitted to Radiation Oncology, a section of the journal Frontiers in Oncology.

Copyright $(2014 \mathrm{Vu}$, Haas, Katz and Witten. This is an open-access article distributed under the terms of the Creative Commons Attribution License (CC BY). The use, distribution or reproduction in other forums is permitted, provided the original author(s) or licensor are credited and that the original publication in this journal is cited, in accordance with accepted academic practice. No use, distribution or reproduction is permitted which does not comply with these terms. 